\title{
Reactive Attachment Disorder of Infancy or Early Childhood
}

\author{
MARGOT MOSER RICHTERS, PH.D., AND FRED R. VOLKMAR, M.D.
}

\begin{abstract}
Since its introduction into DSM-III, reactive attachment disorder has stood curiously apart from other diagnoses for two reasons: it remains the only diagnosis designed for infants, and it requires the presence of a specific etiology. This paper describes the pattern of disturbances demonstrated by some children who meet DSM-III-R criteria for reactive attachment disorder. Three suggestions are made: (1) the sensitivity and specificity of the diagnostic concept may be enhanced by including criteria detailing the developmental problems exhibited by these children; (2) the etiological requirement should be discarded given the difficulties inherent in obtaining complete histories for these children, as well as its inconsistency with ICD-10; and (3) the diagnosis arguably is not a disorder of attachment but rather a syndrome of atypical development. J. Am. Acad. Child Adolesc. Psychiatry, 1994, 33, 3: 328-332. Key Words: reactive attachment disorder, maltreatment, DSM-III-R
\end{abstract}

Reactive attachment disorder (RAD) was included in DSM-III in 1980 (American Psychiatric Association, 1980), reflecting an awareness of a body of literature on the effects of deprivation and institutionalization on infants and young children (Bakwin, 1949; Bowlby, 1944; Provence and Lipton, 1962; Rutter, 1972; Skeels and Dye, 1939; Skuse, 1984; Spitz, 1945; Tizard and Rees, 1975). Multiple terms have been used to refer to manifestations of the condition including failure to thrive, nonorganic failure to thrive, psychosocial dwarfism, maternal deprivation, anaclitic depression, hospitalism, and reactive attachment disorder, with differences in terms reflecting the interests of different investigators.

The name of the disorder emphasized problems with attachment but the criteria included symptoms such as failure to thrive, a lack of developmentally appropriate

Accepted August 10, 1993.

Dr. Richters is a NIMH postdoctoral fellow in Psychology and Dr. Volkmar is the Harris Associate Professor of Child Psychiatry, Psychology and Pediatrics, Yale Child Study Center, Yale University, New Haven, CT.

The authors thank John Richters, Ph.D., and Gary Racusin, Ph.D., for their editorial assistance.

The names and certain details of the cases have been altered to protect the identity and confidentiality of the families involved.

Reprint requests to Dr. Margot Moser Richters, Western Psychiatric Institute

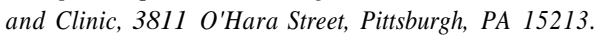

$0890-8567 / 94 / 3303-0328 \$ 033001001994$ by the American Academy of Child and Adolescent Psychiatry. social responsiveness, apathy, and onset before 8 months. Only one criterion addressed the quality of mother-infant attachment.

Several aspects of the definition were unsatisfactory (Rutter and Shaffer, 1980), and substantial modifications were made in DSM-III-R (American Psychiatric Association, 1987): the age of onset was raised to age 5 years, consistent with data on the development of selective attachments (although the diagnosis could still be made as early as the first month of life); the failureto-thrive symptoms were no longer defining features; and the nature of problems in social responsivity were delineated further. The role of psychosocial factors was emphasized by (1) requiring evidence of pathogenic care and (2) the notion that the condition was reversible given appropriate treatment. Children with either mentai retardation or pervasive developmental disorder were excluded from the diagnosis.

There has been very little empirical work on this concept as such. Case reports of individuals who have experienced grossly pathogenic care have appeared but have not explicitly referred to RAD. Prevalence rates, extrapolated from the maltreatment literature, have been estimated at approximately 1\% (Zeanah and Emde, in press).

Controversies around the DSM-III-R definition include (1) the requirement for a specific etiology, (2) inconsistency with the ICD-10(World Health Organization, 1990) definition in this regard, and (3) the suggestion that the term "maltreatment syndrome 
may be more accurate. It is also unclear why children with mental retardation are excluded since mental retardation is presumably not a protective factor, it alone does not account for the presence of disturbed social relatedness (Volkmar, in press), and it is inconsistent with ICD-10, which excludes only pervasive developmental disorder.

Clinicians and researchers agree that children who have experienced abuse, neglect, or frequent disruptions in primary caregivers often exhibit varying degrees of cognitive, physical, and social-emotional delays (Aber and Allen, 1987; Alessandri, 1991; Cicchetti and Barnett, 1991; Erichon et al., 1989; Hoffman-Plotkin and Twentyman, 1984; Rutter and Tuma, 1988; Salzinger et al., 1993). There is also evidence to suggest that some of these children respond to therapeutic interventions (Harris, 1982; Powell et al., 1973). After reviewing the available evidence, Volkmar (in press) suggested that the diagnosis of RAD should be retained in DSM-IV because it characterizes a pattern of disturbance that is not encompassed by other existing diagnostic categories, it identifies a condition that potentially endures in the child (i.e., apart from the parent-child dyad), and it is clearly an important target for both intervention and research.

The following cases are of children who meet current criteria for RAD. These may help clarify issues warranting further research.

\section{CASE 1}

Rebecca was 6 years old when her mother and stepfather brought her in for psychiatric evaluation. Her early childhood was replete with frequent changes in primary caregivers. When she was 2 years old, her parents divorced and her father received custody while her mother remained overseas with the armed forces. During her 8-month stay with her father, in what was described as a chaotic environment, Rebecca had no contact with her mother. Mounting legal problems encountered by her father led to Rebecca's temporary placement with her grandparents before her mother resumed care.

Rebecca's physical development was normal but her language, cognitive, and social development were delayed. Examination identified expressive and receptive language deficits including poor articulation and comprehension. Cognitive testing suggested mild mental retardation.
Socially, Rebecca appeared immature and inappropriate. Her interactions were dominated by indiscriminate sociability. In addition, Rebecca had difficulty modulating her affect, particularly anger, and often required assistance to regain control. She was extremely impulsive and demonstrated poor attention and concentration.

Noticeable changes occurred within months after she rejoined her mother including improved verbal skills and a decrease in disruptive behaviors, although attentional and social deficits persisted.

\section{CASE 2}

Jimmy had experienced multiple changes in caregivers during his early childhood. He moved often as his parents were assigned to different military bases, and because of marital discord, the responsibility for caregiving shifted frequently. His parents eventually divorced and from ages 3 to 8 years, Jimmy lived with his mother and new stepfather. This home environment was quite chaotic and probably abusive; after an investigation by child protective services, and to avoid legal proceedings, Jimmy was returned to the care of his father and stepmother.

Upon reunion, Jimmy's father noted unusual behaviors and developmental problems. Jimmy's speech was characterized by some echolalia and disorganization. We was unable to engage in basic self-care activities, exhibited self-injurious behaviors, and needed constant supervision. His social interactions were marked by gaze aversion, unprovoked aggression, and an intense dislike of being touched. His affective responses were unpredictable and labile. He also experienced sleep disturbances and frequent nightmares. In school, teachers noted poor attention, poor motor coordination, and self-stimulatory behaviors. Cognitive testing conducted at age 6 placed Jimmy in the borderline range of intelligence.

At follow-up 1 year after rejoining his father, Jimmy showed significant gains in overall functioning. Cognitive testing placed him in the average range of intelligence, although some learning difficulties remained, and there was marked improvement in his language skills. While there was a decrease in maladaptive behavior, his paucity of adaptive skills persisted, particularly in the social domain where his interactions remained odd, stilted, and indiscriminate, with poor integration of social-emotional cues. 


\section{CASE 3}

Maria first received treatment when she was 5 years old, as a result of severe behavioral problems in school. She was referred for inpatient services at age 8 after a child protective services investigation substantiated allegations of physical abuse. Maria had a complicated history beginning with her mother's problematic pregnancy, during which she miscarried Maria's twin at 20 weeks. During Maria's birth, her biological father severely beat two older siblings and was subsequently incarcerated.

Consequently, Maria was sent to foster care and spent her first 8 months of life living with a relative. Her mother, suffering from depression, visited sporadically. Maria's reunion with her mother lasted until she was 4 years old, when she was sent to live with her godmother while her mother looked for work in another town. This arrangement was abruptly terminated after complaints about Maria's oppositional behavior. Her mother resumed care for several months before sending Maria to live with Maria's maternal grandmother. This placement was also short-lived because of Maria's behavior problems.

According to her mother, Maria developed normally until age 2 or 3 years, when she began to exhibit behavior problems. Her mother and her teachers described Maria as aggressive, oppositional, and impulsive. According to school reports, Maria had few friends. She alienated classmates by stealing from them and initiating physical fights but usually denied guilt and showed no remorse for her behaviors.

Maria also exhibited erratic and unpredictable mood swings. Her behavior would fluctuate from clinging and hugging to hitting and swearing. During psychiatric assessment, Maria stated concerns about being "bad" and "crazy" and reported occasionally hearing a voice telling her to turn on the television. She also reported transient suicidal ideations and appeared disturbed by her lack of peer relationships.

Unlike the previous two cases, Maria did not evidence any cognitive deficits. Her developmental delays were primarily in the social and behavioral domains. She exhibited poor daily living skills, below-average coping abilities, limited interpersonal skills, and many maladaptive behaviors. Maria continues to live with her mother.

\section{CASE 4}

Shannon was evaluated after being placed in temporary foster care by child protective services. Several children had died under mysterious circumstances while in the care of Shannon's mother. Two other children had been placed in foster homes after unexplained injuries.

On examination at age 4 years, Shannon appeared to be much younger than her stated age. She was at the 15 th percentile for height and the 10 th percentile for weight. She exhibited mild delays in fine and gross motor skills, as well as problem-solving skills. Her performance was most delayed in the areas of language, self-care, and social relatedness. Her articulation was poor and her vocabulary was limited to approximately 20 recognizable words. She demonstrated limited receptive skills and could not follow simple verbal instructions. Shannon was not toilet trained and could not feed herself with a spoon. Socially, she did not understand turn-taking in play and exhibited little symbolic play. She was quite withdrawn and did not easily engage with others. Affectively, she was constricted, anxious, depressed, and apathetic.

Although significant developmental delays persisted at follow-up, Shannon showed marked improvement in her language, self-care, and social skills. She also exhibited much brighter affect.

\section{DISCUSSION}

The children described here experienced grossly pathogenic care and exhibited multiple developmental difficulties. Features not identified in the current criteria for RAD but shared by most of these children included unusual patterns of language and motor delays, failed acquisition of age-appropriate self-care skills, poor attention and concentration, emotional lability, aggressivity, impulsivity, and oppositionality. These complicated and atypical symptom pictures presented a diagnostic dilemma. The children appeared autisticlike in some respects but were more socially related than autistic children and were more behaviorally deviant than children with language disorders. Using current nosology, the evaluating clinicians resolved the dilemma by applying multiple diagnoses in addition to RAD (Specifically, the diagnoses for case 1 included attention-deficit hyperactivity disorder and developmental expressive language disorder; case 2 carried 
attention-deficit hyperactivity disorder, post-traumatic stress disorder, and developmental expressive language disorder; case 3 received oppositional-defiant disorder, post-traumatic stress disorder, parent-child problem, and a rule out for psychotic disorder not otherwise specified; and case 4 garnered dysthymia and both developmental expressive and receptive language disorder.) It is incumbent upon researchers to determine whether (I) there is a constellation of symptoms contributing to a single, parsimonious explanation or if, in fact, these children are afflicted with multiple Axis I and Axis I1 disorders; and (2) whether the inclusion of more symptoms might increase the sensitivity and specificity of the diagnostic concept.

As stipulated in DSM-III-R, a response to therapeutic intervention is considered confirmatory evidence for the diagnosis of RAD. In the three cases involving significant environmental changes reported here, the children indeed demonstrated marked improvement. While this seems an imprecise method and clearly requires empirical validation, response to treatment may help us understand how RAD differs from other disorders, particularly the pervasive developmental disorders, and should continue to be a marker for the diagnosis, if not a necessary diagnostic feature.

The etiological requirement, i.e., of pathological care, continues to be controversial. From a practical aspect, the children described above demonstrate how the caregiving histories are often complicated, sketchy, and incomplete at the time of assessment, making it difficult to apply the diagnosis. Furthermore, Volkmar (in press) notes how the criterion impedes our ability to determine whether the behavioral features exist in the absence of severe adversity. Given that inadequate caregiving exists on a continuum from inexperienced to severely abusing parents, it is imperative that research demonstrating the relevance and usefulness of retaining a specific etiology is conducted.

The question posed by developmentalists is whether these children suffer from disordered attachments or a syndrome of maltreatment. From their perspective, the defining feature of attachment disorders is a profound disturbance in a child's use of a primary caregiver as a source of safety and security (Zeanah et al., 1993). Zeanah and colleagues (1993) have proposed a set of criteria for attachment disorders that go well beyond the attachment categories defined by Ainsworth et al.
(1978). Diagnosis requires an assessment of the childcaregiver relationship in areas such as comfort seeking, exploratory behavior, affectionate responses, and cooperativeness, and evidence that the disorder resides within the child (Zeanah and Emde, in press). This orientation is distinctly different from the current DSM criteria, which focus on pervasive disturbances in social relatedness and pay little attention to characteristics of the primary attachment.

Powell and Bettes (1992), writing from another perspective on the attachment question, note that studies have not established the presence of specific attachment disorders among children diagnosed with RAD. In addition, they point out that the nonorganic failureto-thrive behaviors included in the diagnosis (i.e., gaze abnormality, general inactivity, lack of reactivity to stimuli, rumination, failure to gain weight) have not been causally linked to defective attachments. In fact, evidence from the child maltreatment literature suggests that while maltreated children are more likely to exhibit insecure and confused patterns of relatedness, they do not necessarily develop a disorder of attachment (Cicchetti and Barnett, 1991; Lynch and Cicchetti, 1991). These authors hypothesize that maltreated children develop various attachment styles in their attempts to cope with inconsistent and problematic parentchild relationships.

The pattern of disturbances exhibited by the children in this paper lends credence to the argument that RAD is not a disorder of attachment as usually defined by developmentalists. The case descriptions conform to the DSM-III-R criteria of disturbed social relatedness across domains and do not identify specific attachment defects in child-caregiver relationships. At the same time, the children described do provide clinical evidence for a constellation of symptoms and atypical development not captured by other diagnostic categories. They appear to represent a subgroup of children whose primary difficulties are in the area of social relatedness that are best explained by defects in social-emotional development versus the neurobiological defects more characteristic of the pervasive developmental disorders. The findings suggest that the multiple deficits expressed in this condition are not intractable but rather are quite responsive to treatment, making detection and diagnosis all the more important; the question of improvement awaits future research. 
At this juncture, integrating the findings from the diverse fields of research will greatly enhance our ability to identify and treat affected children. In addition, developing a reliable and valid diagnosis will require longitudinal, prospective studies that will help characterize the disorder, validate the criteria, and document developmental trajectories.

\section{REFERENCES}

Aber JL, Allen JP (1987), Effects of maltreatment on young children's social emotional development: an attachment theory perspective. Developmental Psychology 23:406-414

Ainsworth MDS, Blehar M, Waters E, Wall S (1978), Patterns of Attachment: A Psychological Study of the Strange Situation. Hillsdale, NJ: Erlbaum

Alessandri SM (1991), Play and social behaviors in maltreated preschoolers. Development and Psychopathology 3:191-206

American Psychiatric Association (1980), Diagnostic and Statistical Manual of Mental Disorders. 3rd edition (DSM-III). Washington, DC: American Psychiatric Association

American Psychiatric Association (1987), Diagnostic and Statistical Manual of Mental Disorders, 3rd edition, revised (DSM-III-R). Washington, DC: American Psychiatric Association

Bakwin H (1949), Emotional deprivation in infants. $\boldsymbol{J}$ Pediatr 35:521

Bowlby J (1944), Forty-four juvenile thieves: their characters and homelife. Int J Psychoanal 25:19-53, 107-1 27

Cicchetti D, Barnett D (1991). Attachment organization in maltreated preschoolers. Development and Psychopathology 3:397-412

Erickson MF, Egeland B, Pianta R (1989), The effects of maltreatment on the development of young children. In: Child Maltreatment, Cicchetti D, Carlson V, eds. New York: Cambridge University Press, pp 647-684

Harris JC (1982). Nonorganic failure-to-thrive syndromes: reactive attachment disorder of infancy and psychosocial dwarfism of childhood. In: Failure to Thrive in Infancy and Early Childhood Accardo PJ, ed. Baltimore, MD: University Park Press, pp 229-242

Hoffman-Plotkin D, Twentyman C T (1984), A multimodal assessment of behavioral and cognitive deficits in abused and neglected preschoolers. Child Dev 55:794-802
Lynch M, Cicchetti D (1991), Patterns of relatedness in maltreated and nonmaltreated children: connections among multiple representational models. Development and Psychopathology 3:207-226

Powell GF, Bettes BA (1992). Infantile depression, nonorganic failure to thrive, and DSM-III-R: a different perspective. Child Psychiatry Hum Dev 22: $185-198$

Powell GF, Hopwood NJ, Barrett ES (1973), Growth hormone studies before and during catch-up growth in a child with emotional deprivation and short stature, J Clin Endocrinol Metab 37:674-679

Provence S, Lipton R (1962), Infants in Institutions. New York: International Universities Press

Rutter M (1972), Maternal Deprivation Reassessed New York: Penguin Books

Rutter M, Shaffer D (1980), DSM-III: a step forward or backward in terms of the classification of child psychiatric disorders? $\boldsymbol{J}$ Am Acad Child Psychiatry 19:371-394

Rutter M, Tuma AH (1988), Diagnosis and classification: some outstanding issues. In: Assessment and Diagnosis in Child Psychopathology Rutter M, Tuma AH, Lann IS, eds. New York: Guilford Press, pp 437-452

Salzinger S, Feldman RS, Hammer M (1993), The effects of physical abuse on children's social relationships. Child Dev 64: 169-1 87

Skeels HM, Dye HB (1939), A study ofthe effects of differential stimulation of mentally retarded children. Proceedings of the American Association Mental Deficiency 44: 114-136

Skuse D (1984), Extreme deprivation in early childhood. I. Diverse outcomes for three siblings from an extraordinary family. J Child Psychol Psychiatry 25:523-541

Spin. R (1945), Hospitalism: an inquiry into the genesis of psychiatric conditions in early childhood. Psychoanal Study Child 1:53-74

Tizard B, Rees J (1975). The effect of early institutional rearing on the behaviour problems and affectional relationships of four-year-old children. J Child Pychol Psychiatry 16:61-73

Volkmar F (in press), Reactive attachment disorders: issues for DSM-IV. In: DSM-IV Source Book. Washington, DC: American Psychiatric Association

World Health Organization (1990), International Classification of Diseases, 10 th ed, Diagnostic Criteria For Research (draft). Geneva: World Health Organization

Zeanah CH, Emde RN (in press), Attachment disorders in infancy and childhood. In: Child and Adolescent Psychiatry, 3rd ed., Rutter M, Hersov L, Taylor E, eds. London: Blackwell

Zeanah CH. Mammen OK, Lieberman AF (1993), Disorders of attachment. In: Handbook of Infant Mental Health, Zeanah $\mathrm{CH}$, ed. New York: Guilford Press, pp 332-349 